of $15.2 \pm 9.5$ years. bDMARD therapy was used for a mean time period of $3.2 \pm 2.5$ years. Eighty three percent of patients were treated in combination therapy and $80 \%$ of patients were seropositive (CCP and/or RF). Both groups did not differ significantly on baseline clinical characteristics (see Table), with 2 exceptions: patients who received Anti-TNF therapies were treated more frequently as first line therapy $(75.2 \%$ vs $53.2 \%, p<0.001)$ and received in a higher proportion combined therapy $(90.9 \%$ vs $75.0 \%, p<0.001)$. A total of $59 \%$ of patient achieved remission at the last visit. Three year remission rates were slightly higher but not significant in patients treated with non-anti TNF therapies vs anti-TNF therapies $(59.6 \%$ vs $53.3 \%, p=N S)$. We did not find significant differences in remission rates according serological status.

Conclusions: In real-life setting, a meaningful proportion of RA patients achieved remission on the last visit. Patients treated with anti-TNF and non-anti TNF therapies had similar baseline characteristics and after a mean time period of treatment of 3 years, achieved similar remission rates.

Disclosure of Interest: None declared

DOI: 10.1136/annrheumdis-2017-eular.5293

\section{AB0405 SAFETY OF RITUXIMAB THERAPY IN AUTOIMMUNE DISEASES:SYSTEMATIC REVIEW AND META-ANALYSIS}

K. Kobayashi ${ }^{1}$, K.M. Minegishi ${ }^{1}$, N. Horita ${ }^{2}$, S. Ohno ${ }^{1}$, H.N. Nakajima ${ }^{3} .{ }^{1}$ Center for Rheumatic Diseases, Yokohama City University Medical Center; ${ }^{2}$ Department of Pulmonology; ${ }^{3}$ Department of Stem Cell and Immune Regulation, Yokohama City University Graduate School of Medicine, Yokohama, Kanagawa, Japan

Background: Treatment with rituximab (RTX), a chimeric CD20 monoclonal antibody, has demonstrated efficacy for patients with several autoimmune diseases. There is a growing concern, however, safety evidence of RTX is still lacking.

Objectives: We conducted to evaluate the safety of rituximab (RTX) for autoimmune diseases.

Methods: A literature review was performed based on the randomized clinical trials (RCTs) that assessed adverse events by comparing RTX and placebo or no treatment for autoimmune diseases. The same add-on treatment for both arms were allowed. Study selection and data extraction were independently conducted in duplicate. Meta-analyses were performed for each outcome separately using fixed model and generic inverse variance method.

Results: In the primary analysis, 16 eligible RCTs, with a total of 4147 patients for five autoimmune diseases $(n=8$ : rheumatoid arthritis, $n=3$ : Sjogren syndrome, $n=1$ : systemic lupus erythematosus, multiple sclerosis, ulcerative colitis, Graves orbitopathy, immune thrombocytopenia) were analyzed. The incidence of infusion related reactions and the human antichimeric antibody (HACA) were higher in RTX group than placebo/no treatment group (OR $1.49,95 \% \mathrm{Cl} 1.25-1.77$ and OR $2.25,95 \% \mathrm{Cl} 1.35-3.76$, respectively). However, there were no significant differences the odds of total adverse events, serious adverse events, withdrawal for adverse events, infections, serious infections, malignancy, and all-cause death between two groups.

Conclusions: Our meta-analysis revealed that RTX was not associated with an increased risk of adverse events except for infusion related reactions and the incidence of HACA compared with placebo.

Acknowledgements:

Disclosure of Interest: None declared

DOI: 10.1136/annrheumdis-2017-eular.5643

\section{AB0406 STABLE EFFICACY AND SAFETY AFTER SWITCHING FROM TOCILIZUMAB INTRAVENOUS TO SUBCUTANEOUS IN RHEUMATOID ARTHRITIS: RESULTS OF A COHORT OF 200 PATIENTS}

L. Joffres ${ }^{1}$, E. Ricard ${ }^{2}$, C. Pereira Gillion ${ }^{3}$, M. Herbette ${ }^{4}$, C. Lucas ${ }^{5}$, J.B. Cren ${ }^{6}$, E. Bergeal ${ }^{7}$, Y. Maugars ${ }^{8}$, C. Saillot ${ }^{2}$, P. Goupille ${ }^{3}$, A. Saraux ${ }^{4}$, A. Perdriger ${ }^{5}$, B. Bouvard ${ }^{6}$, E. Solau Gervais ${ }^{1,9} \cdot{ }^{1}$ Rheumatology, University Hospital, Poitiers; ${ }^{2}$ Rheumatology, General Hospital, Orleans; ${ }^{3}$ Rheumatology, University Hospital, Tours; ${ }^{4}$ Rheumatology, University Hospital, Brest; ${ }^{5}$ Rheumatology, University Hospital, Rennes; ${ }^{6}$ Rheumatology, University Hospital, Angers; ${ }^{7}$ Medical information, General Hospital, la Rochelle; ${ }^{8}$ Rheumatology, University Hospital, Nantes; ${ }^{9}$ LITEC, Immunology Laboratory, Poitiers, France

Background: Intravenous tocilizumab has been used since 2009 in Europe for the treatment of active rheumatoid arthritis. Since 2015, a subcutaneous formulation is available. The switch from a monthly, intravenous, with dose adjusted for bodyweight treatment to a weekly, subcutaneous, fixed dose, leads to various questions about efficacy and toxicity.

Objectives: The objectives were to evaluate the efficacy maintenance (maintenance rate and DAS28 variation), the safety, the dose variation after the switch and the characteristics of patients switching to the subcutaneous form respect to those following with the intravenous tocilizumab.

Methods: Multicenter and retrospective study was performed from a cohort of 203 patients undergoing intravenous tocilizumab from the rheumatology unit of 7 university hospitals between September 2015 and May 2016. Assessment has been done on the records, effectiveness was assessed using the DAS28, adverse events and reasons for staying on IV form were reported.
Results: On the 203 records analyzed, 3 were secondarily excluded. Of the 200 patients, 77 have switched for the subcutaneous form. Mean age of the 200 patients was 58 years $(+/-13.3)$ with 155 women $(78 \%)$ and the mean duration of rheumatoid arthritis was 14 years $(+/-10.4) .72 \%$ of patients received a standard intravenous dose $(8 \mathrm{mg} / \mathrm{kg} / \mathrm{month})$ at baseline.

At the first visit after the prescription of the subcutaneous treatment, 58 patients on $65(89 \%)$ maintained the treatment. The mean DAS28 was $1.53(+/-1.00)$ at baseline and $1.19(+/-0.78)$ at $\mathrm{T} 1$ (45 patients). Three patients received a reduced subcutaneous dose of $162 \mathrm{mg} / 2$ weeks following a reduced IV dose $(<8$ $\mathrm{mg} / \mathrm{kg} / \mathrm{month}$ ) and maintained the subcutaneous treatment.

About safety, there was no new case of neutropenia $<1000 / \mathrm{mm}^{3}$. One severe adverse effect occurred (gastro intestinal perforation).

Regard to the dose variation, for the 77 patients switching, the mean difference between intravenous and subcutaneous dose was $+29 \mathrm{mg} / \mathrm{week}(+/-35 \mathrm{mg})$ with the subcutaneous tocilizumab.

Reasons for staying on IV form were essentially: the subcutaneous tocilizumab was not proposed in $55 \%$ of the cases and $17 \%$ of patients refused the subcutaneous form.

Conclusions: $89 \%$ of patients maintained the subcutaneous treatment after 4 months; efficacy was maintained in patients who received a reduced subcutaneous dose. Despite the higher dose after the switch $(+29 \mathrm{mg} /$ week), there was no new case of neutropenia.

Disclosure of Interest: None declared

DOI: 10.1136/annrheumdis-2017-eular.6008

\section{AB0407 COMPARATIVE EFFECTIVENESS OF TOCILIZUMAB (TCZ) MONOTHERAPY WITH TUMOR NECROSIS FACTOR INHIBITORS (TNFI) IN COMBINATION WITH VARYING DOSES OF METHOTREXATE (MTX) IN PATIENTS WITH RHEUMATOID ARTHRITIS}

L.R. Harrold ${ }^{1,2}$, G.W. Reed ${ }^{1,2}$, J. Best $^{3}$, S. Zlotnick ${ }^{3}$, G. Persuitte ${ }^{2}$, J.M. Kremer $2,4 .{ }^{1}$ University of Massachusetts Medical School, Worcester; ${ }^{2}$ Corrona, LLC, Southborough; ${ }^{3}$ Genentech, Inc, South San Francisco; ${ }^{4}$ Albany Medical College and The Center for Rheumatology, Albany, United States

Background: Clinical studies have shown that the efficacy of TCZ monotherapy (TCZ mono) is superior to that of TNFi monotherapy and comparable to that of TCZ in combination with MTX

Objectives: To compare the effectiveness of TCZ mono vs TNFi plus varying doses of MTX in patients with rheumatoid arthritis (RA) and prior exposure to TNFi in routine clinical practice.

Methods: Eligible participants were TCZ-naïve patients from the Corrona RA registry who had prior exposure to $\geq 1 \mathrm{TNFi}$, initiated TCZ mono or a TNFi + MTX between 2010 and 2016 and had a 6 -month follow-up visit. The primary outcome was mean change from baseline in Clinical Disease Activity Index (CDAI) at 6 months. Secondary outcomes included achievement of low disease activity (LDA; CDAI $\leq 10)$ at 6 months. Patients initiating a TNFi + MTX were grouped by MTX dose ( $\leq 10 \mathrm{mg} ;>10$ to $\leq 15 \mathrm{mg} ;>15$ to $\leq 20 \mathrm{mg} ;>20 \mathrm{mg}$ ); outcomes in each group were compared with those initiating TCZ mono using trimmed populations, excluding patients outside the propensity score (PS) distribution overlap (not on common support). The PS included age, sex, race, body mass index, smoking status, work status, disease duration, concomitant prednisone use/dose, prior biologic use, American College of Rheumatology functional class and baseline modified Health Assessment Questionnaire, CDAl and patient pain scores. As a sensitivity analysis, stratified-matched populations were created (stratified by 1 vs $\geq 2$ prior biologics, then matched on PS). Linear and logistic regression models were estimated in the trimmed populations, adjusting for the same covariates as in the PS. Results: Baseline demographics were generally comparable between the TNFi + MTX groups and their matched TCZ mono groups. Overall, the mean age was 54 to 59 years, and the mean disease duration was 10.5 to 15 years. A higher proportion of patients initiating TCZ mono had received $\geq 3$ prior biologics compared with those initiating TNFi + MTX. Patients initiating TCZ mono had significantly longer mean disease duration than those initiating TNFi $+\mathrm{MTX}>15$ to $\leq 20 \mathrm{mg}$ ( 13.0 vs 10.5 years) or TNFi + MTX $>20 \mathrm{mg}$ (12.3 vs 9.3 years) and a higher mean baseline CDAl than those initiating TNFi + MTX $\leq 10 \mathrm{mg}$ (28.1 vs 25.4). Patients in all groups had improvement in CDAl scores at 6 months. In adjusted models, improvement in CDAI and the likelihood of achieving LDA were similar between the TCZ mono group and all TNFi + MTX groups (Table). Similar results were observed in the PS-matched cohorts.

Conclusions: TCZ mono was as effective as TNFi + MTX, regardless of MTX dose, for improving disease activity in patients with prior TNFi exposure. These data suggest that TCZ mono is an effective treatment option for patients with RA who cannot tolerate or prefer not to use MTX.

Acknowledgements: This study is sponsored by Corrona, LLC. Corrona, LLC, has been supported through contracted subscriptions in the past 2 years by AbbVie, Amgen, BMS, Crescendo, Eli Lilly and Company, Genentech, GSK, Horizon Pharma USA, Janssen, Momenta Pharmaceuticals, Novartis, Pfizer, Roche and UCB.

Disclosure of Interest: L. Harrold Shareholder of: Corrona, LLC, Grant/research support from: Pfizer, Consultant for: Roche, Employee of: University of Massachusetts Medical School; Corrona, LLC, G. Reed Shareholder of: Corrona, LLC, Employee of: Corrona, LLC, J. Best Employee of: Genentech, Inc, S. Zlotnick 


\begin{tabular}{|c|c|c|c|c|}
\hline & \multicolumn{2}{|c|}{ Change in CDAI } & \multicolumn{2}{|c|}{ Achievement of LDA } \\
\hline & $\begin{array}{l}\text { Unadjusted } \\
\text { Mean (SD) }\end{array}$ & $\begin{array}{c}\text { Adjusted } \\
\beta(95 \% \mathrm{Cl})^{*}\end{array}$ & $\begin{array}{l}\text { Unadjusted } \\
\text { Response } \\
\text { Rate, n (\%) }\end{array}$ & $\begin{array}{c}\text { Adjusted } \\
\text { OR }(95 \% \text { Cl)* }\end{array}$ \\
\hline $\begin{array}{l}\text { TCZ mono } \\
(n=283)\end{array}$ & $-9.7(14.6)$ & - & $82(29)$ & - \\
\hline $\begin{array}{l}T N F i+M T X \\
\leq 10 \mathrm{mg} \\
(n=108)\end{array}$ & $-7.8(13.6)$ & $\begin{array}{c}-0.15 \\
(-2.92 \text { to } \\
2.62)\end{array}$ & $33(31)$ & $\begin{array}{c}1.22 \\
(0.71 \text { to } 2.10)\end{array}$ \\
\hline $\begin{array}{l}\text { TCZ mono } \\
(n=300)\end{array}$ & $-9.6(14.5)$ & - & $88(29)$ & - \\
\hline $\begin{array}{l}\text { TNFi }+M T X \\
>10 \text { to } \leq 15 \mathrm{mg} \\
(n=186)\end{array}$ & $-9.0(14.2)$ & $\begin{array}{c}-0.3 \\
(-2.83 \text { to } \\
2.22)\end{array}$ & $70(38)$ & $\begin{array}{c}0.94 \\
(0.60 \text { to } 1.48)\end{array}$ \\
\hline $\begin{array}{l}\text { TCZ mono } \\
(n=292)\end{array}$ & $-9.6(14.7)$ & - & $85(29)$ & - \\
\hline $\begin{array}{l}\text { TNFi + MTX } \\
>15 \text { to } \leq 20 \mathrm{mg} \\
(n=273)\end{array}$ & $-6.9(12.8)$ & $\begin{array}{c}-1.65 \\
(-3.84 \text { to } \\
0.54)\end{array}$ & $73(27)$ & $\begin{array}{c}1.4 \\
\text { (0.89 to } 2.18)\end{array}$ \\
\hline $\begin{array}{l}\text { TCZ mono } \\
(n=285)\end{array}$ & $-9.7(14.7)$ & - & $85(30)$ & - \\
\hline $\begin{array}{l}\text { TNFi + MTX } \\
>20 \mathrm{mg} \\
(n=107)\end{array}$ & $-8.4(15.0)$ & $\begin{array}{c}-1.43 \\
(-5.12 \text { to } \\
2.25)\end{array}$ & $32(30)$ & $\begin{array}{c}1.26 \\
(0.70 \text { to } 2.25)\end{array}$ \\
\hline \multicolumn{5}{|c|}{$\begin{array}{l}\text { CDAI, Clinical Disease Activity Index; LDA, low disease activity; MTX, methotrexate; } \\
\text { OR, odds ratio; TCZ, tocilizumab; TNFi, tumor necrosis factor inhibitor. } \\
\text { "TCZ compared with TNFi + MTX. Adjusted for sex, age, race (white vs nonwhite), } \\
\text { disabled, retired, baseline CDAI, baseline modified Health Assessment } \\
\text { Questionnaire, baseline patient pain scores, baseline prednisone use/dose, } \\
\text { baseline body mass index, prior biologic use, prior TNFi use and American College } \\
\text { of Rheumatology functional class. }\end{array}$} \\
\hline
\end{tabular}

Employee of: Genentech, Inc, G. Persuitte Employee of: Corrona, LLC, J. Kremer Shareholder of: Corrona, LLC, Consultant for: AbbVie; Amgen; Bristol-Meyers Squibb; Genentec, Inc; GlaxoSmithKline; Lilly; Pfizer; Regeron; Sanofi, Employee of: Corrona, LLC

DOI: 10.1136/annrheumdis-2017-eular.3295

\section{AB0408 COMPARATIVE EFFECTIVENESS OF ABATACEPT VERSUS TNFI IN PATIENTS WITH RHEUMATOID ARTHRITIS WHO ARE CCP+ IN THE UNITED STATES CORRONA REGISTRY}

L. Harrold $^{1}$, H. Litman ${ }^{2}$, S. Connolly ${ }^{3}$, E. Alemao ${ }^{3}$, K. Price ${ }^{3}$, S. Kelly ${ }^{3}$, S. Rebello ${ }^{2}$, W. Hua ${ }^{2}$, J. Kremer ${ }^{4}{ }^{1}$ University of Massachusetts, Worcester; ${ }^{2}$ Corrona, LLC, Southborough; ${ }^{3}$ Bristol-Myers Squibb, Princeton; ${ }^{4}$ Albany Medical College and The Center for Rheumatology, Albany, United States

Background: Anti-cyclic citrullinated peptide positivity $(\mathrm{CCP}+)$ is associated with a better response to abatacept (ABA) than anti-CCP negativity in patients (pts) with RA ${ }^{1,2}$; however, there are no head-to-head or comparative effectiveness research studies available evaluating responses to biologics in CCP+ pts in a real-world setting.

Objectives: To compare the effectiveness of ABA vs a TNF inhibitor (TNFi) in pts with RA who are CCP+.

Methods: We identified adult pts with RA from a large observational US cohort (1 Dec 2005-31 Aug 2016) who initiated ABA or a TNFi and who were CCP+ $(\geq 20$ $\mathrm{U} / \mathrm{mL}$ ) at or prior to initiation. Both groups had to have no prior exposure to other non-TNFi biologics or targeted synthetic DMARDs. TNFi initiators were excluded if they had prior use of ABA. Using propensity score matching (1:1) stratified by prior TNFi use $(0,1$ and $2+)$, effectiveness at 6 months after initiation was evaluated. Mean change in CDAl over 6 months following initiation was the primary outcome, and secondary outcomes were: achievement of remission (CDAl $\leq 2.8$ ), modified (m)ACR20, 50 and 70 responses and achievement of LDA/remission (CDAl $\leq 10$ ) in those with moderate/high disease activity at initiation. A subset analysis was performed to consider separately pts who were biologic naïve and those who were biologic experienced at initiation.
Results: The 330 pairs of propensity score-matched ABA and TNFi initiators had no substantial differences in baseline characteristics. Both treatment groups had similar mean change in CDAl at 6 months as well as achievement of LDA, remission and mACR20/50/70 responses (Table). Among the 97 matched biologic-naïve pairs, there was no significant difference in change in CDAl for ABA initiators vs TNFi initiators $(p=0.19)$. However, in the 233 matched biologicexperienced pairs, those initiating $A B A$ had a greater improvement in mean change in CDAI ( $p=0.033)$ and were more likely to achieve an mACR50 response $(p=0.014)$.

Conclusions: Pts with RA who were CCP+ and received either ABA or TNFi had a substantial improvement in clinical disease activity. In the overall propensity score-matched sample, similar outcomes were observed for both treatment groups. However, analysis of the biologic-experienced cohort found that ABA initiators had a greater improvement in disease activity than TNFi initiators.

References:

[1] Sokolove J, et al. Ann Rheum Dis 2016:75:709-14.

[2] Harrold LR, et al. Ann Rheum Dis 2016;75(Suppl 2):505-6.

Disclosure of Interest: L. Harrold Shareholder of: Corrona, LLC, Grant/research support from: Pfizer, Consultant for: Roche, Employee of: Corrona, LLC, H. Litman Employee of: Corrona, LLC, S. Connolly Shareholder of: Bristol-Myers Squibb, Employee of: Bristol-Myers Squibb, E. Alemao Shareholder of: Bristol-Myers Squibb, Employee of: Bristol-Myers Squibb, K. Price Employee of: Bristol-Myers Squibb, S. Kelly Shareholder of: Bristol-Myers Squibb, Employee of: Bristol-Myers Squibb, S. Rebello Employee of: Corrona, LLC, W. Hua Employee of: Corrona, LLC, J. Kremer Shareholder of: Corrona, LLC, Grant/research support from: AbbVie, Genentech, Lilly, Novartis, Pfizer, Consultant for: AbbVie, Amgen, BristolMyers Squibb, Genentech, GSK, Lilly, Medlmmune, Pfizer, Sanofi, Employee of: Corrona, LLC

DOI: 10.1136/annrheumdis-2017-eular.1643

\section{AB0409 CORTICOSTEROID-SPARING IN PATIENTS WITH RHEUMATOID ARTHRITIS ON TOCILIZUMAB: FIRST EXPERIENCE OF BAB -EL- OUED HOSPITAL}

M.A. Ifticene, H. Hafirassou, R. Benaziez, F. Mechid, F. Hanni, C. Dahou Makhloufi. Hospital, algiers, Algeria

Background: Tocilizumab (TCZ) is a monoclonal antibody directed against the IL-6 receptors. This treatment (TRT) allows for the cortisone weaning in preventing of its complications.

Objectives: The goal of this study is to evaluate the corticosteroid sparing in patients with RA treated with TCZ.

Methods: Prospective, descriptive study of patients hospitalized between 2012 and 2016, the diagnosis was made according to the ACR 1987 ACR/EULAR 2010 criteria. Included, are the patients treated with TCZ for at least 3 months associated with corticosteroids.

We have studied the following: the epidemiology, the associated DMARDs, the average DAS28VS, the average dosage of prednisone-equivalent and the percentage of patients with decreased or interrupted corticosteroids at M0, M3, M6 and M12.

Results: 26 patients (sex ratio: 0.7 ) treated with $\mathrm{TCZ}$ and corticosteroids, average age is 43.4 years (range 30-62). Average duration of the development of RA: $9.1 \pm 6.4$ years. DMARDs was associated in 15 patient.

At baseline, $46.2 \%$ of patients were on $10 \mathrm{mg} /$ day of cortisone, the average dose of prednisone-equivalent was at $7.7 \pm 3.6 \mathrm{mg}$ at $\mathrm{M} 0,5.3 \pm 3.2 \mathrm{mg}$ at M3, $4.6 \pm 2.3 \mathrm{mg}$ at $\mathrm{M} 6,2.6 \pm 2.6 \mathrm{mg}$ at $\mathrm{M} 12$ with a statistically significant difference $(\mathrm{p}=0.000003)$. The average DASVS28 activity index was $5.6 \pm 0.9$ at M0, $3.5 \pm 1.3$ at M3, $3.04 \pm 1.2$ at M6 and $2.6 \pm \mathrm{M} 6$ at M12 with a statistically significant difference $(\mathrm{p}<0.000001)$. Corticosteroid treatment was stopped in 12 patients after 1 year of treatment.

Conclusions: Through this study we note that the TRT using TCZ has enabled a significant reduction in the dose of corticosteroids. Stopping prednisone was possible in $50 \%$ of patients after 1 year of biotherapy.

Disclosure of Interest: None declared

DOI: 10.1136/annrheumdis-2017-eular.3965

$\underline{\text { Abstract AB0408 - Table } 1}$

\begin{tabular}{|c|c|c|c|c|c|c|c|c|c|}
\hline & \multicolumn{3}{|c|}{ Total population } & \multicolumn{3}{|c|}{ Biologic naive } & \multicolumn{3}{|c|}{ Biologic experienced } \\
\hline & $\begin{array}{c}\mathrm{CCP}+ \\
\text { abatacept initiators } \mathrm{n}=330 \\
\mathrm{n}=330\end{array}$ & $\begin{array}{c}\text { CCP+ } \\
\text { TNFi initiators } \\
\mathrm{n}=330\end{array}$ & & $\begin{array}{c}\mathrm{CCP}+ \\
\text { abatacept initiators } \\
\mathrm{n}=97\end{array}$ & $\begin{array}{c}\mathrm{CCP}+ \\
\text { TNFi initiators } \\
\mathrm{n}=97\end{array}$ & & $\begin{array}{c}\mathrm{CCP}+ \\
\text { abatacept initiators } \\
n=233\end{array}$ & $\begin{array}{c}\mathrm{CCP}+ \\
\text { TNFi initiators } \\
\mathrm{n}=233\end{array}$ & \\
\hline Primary outcome: & Mean ( \pm SE) & Mean $( \pm S E)$ & $p$ value ${ }^{\star}$ & Mean $( \pm$ SE) & Mean ( \pm SE) & $p$ value* & Mean $( \pm$ SE) & Mean $( \pm S E)$ & $p$ value ${ }^{*}$ \\
\hline Change in CDAI & $-9.9( \pm 0.8)$ & $-8.5( \pm 0.8)$ & 0.24 & $-9.8( \pm 1.4)$ & $-12.3( \pm 1.4)$ & 0.19 & $-9.9( \pm 1.0)$ & $-7.0( \pm 1.0)$ & 0.033 \\
\hline Secondary outcomes: & Response rate (\%) & Response rate (\%) & $p$ value $^{\dagger}$ & Response rate (\%) & Response rate (\%) & $p$ value $^{\dagger}$ & Response rate (\%) & Response rate (\%) & $p$ value ${ }^{\dagger}$ \\
\hline LDA & 41.3 & 39.7 & 0.69 & 50.0 & 57.0 & 0.36 & 37.6 & 32.1 & 0.26 \\
\hline Remission & 15.5 & 14.8 & 0.83 & 19.6 & 21.6 & 0.72 & 13.7 & 12.0 & 0.58 \\
\hline mACR20 & 36.4 & 36.4 & $>0.99$ & 40.2 & 45.4 & 0.47 & 34.8 & 32.6 & 0.62 \\
\hline mACR50 & 24.8 & 21.5 & 0.31 & 26.8737 .1 & 0.12 & 24.0 & 15.0 & 0.014 & \\
\hline mACR70 & 13.6 & 10.6 & 0.23 & 17.5 & 19.6 & 0.71 & 12.0 & 6.9 & 0.057 \\
\hline
\end{tabular}

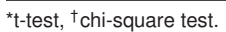

